\title{
Efficacy of prolonged entecavir monotherapy in treatment-naïve chronic hepatitis B patients exhibiting a partial virologic response to entecavir
}

\author{
Han Na Choi, Jeong Eun Song, Hyeon Chul Lee, Hyeong Ho Jo, Chang Hyeong Lee, and Byung Seok Kim \\ Department of Internal Medicine, Catholic University of Daegu School of Medicine, Daegu, Korea
}

Background/Aims: The optimal management of patients exhibiting a partial virologic response (PVR) to entecavir (ETV) has not been determined. The aim of this study was to determine the long-term efficacy of prolonged ETV monotherapy in treatment-naïve chronic hepatitis B (CHB) patients exhibiting a PVR to ETV therapy.

Methods: This study included 364 treatment-naïve CHB patients treated with ETV for $\geq 48$ weeks and who received continuous ETV monotherapy for $\geq 96$ weeks. PVR was defined as a decrease in serum hepatitis B virus (HBV) DNA of more than $2 \log _{10} \mathrm{IU} / \mathrm{mL}$ from baseline but with detectable HBV DNA by real-time PCR assay at week 48 .

Results: Fifty-two of the 364 patients (14.3\%) showed a PVR. Among them, 41 patients received continuous ETV monotherapy for $\geq 96$ weeks (median duration 144 weeks, range 96-312 weeks), and 40 of these patients (95\%) achieved a virologic response $(\mathrm{VR}, \mathrm{HBV}$ DNA $<20 \mathrm{IU} / \mathrm{mL}$ ) during prolonged ETV monotherapy (median duration 78 weeks, range 60-288 weeks). The cumulative probabilities of a VR at weeks 96,144 , and 192 from treatment initiation were $78.0 \%$, 92.7\%, and 95.1\%, respectively. The VR rate was 97.2\% (35/36) in HBeAg-positive patients and 100\% (5/5) in HBeAgnegative patients. In multivariate analysis, $\mathrm{HBeAg}$ positivity (odds ratio [OR], 9.231; 95\% confidence interval [Cl], $1.03-82.91 ; P=0.047)$ and a high baseline HBV DNA level $(\mathrm{OR}, 0.170 ; 95 \% \mathrm{Cl}, 0.08-0.37 ; P=0.000)$ were independently associated with a delayed virologic response. No patient developed genotypic resistance to ETV during follow-up.

Conclusions: Long-term ETV monotherapy is effective for achieving a VR in treatment-naïve CHB patients exhibiting a PVR to ETV. HBeAg positivity and high baseline HBV DNA level were independently associated with a delayed virologic response. (Clin Mol Hepatol 2015;21:24-31)

Keywords: Chronic hepatitis B; Entecavir; Partial virologic response

\section{INTRODUCTION}

Ultimately, the treatment for chronic hepatitis B (CHB) aims to suppress hepatitis B virus (HBV) replication, relieve inflammation, prevent fibrosis and hepatocellular carcinoma (HCC), and increase the survival rate. ${ }^{1,2}$ However, chronic HBV infection is not completely eradicated due to persistence of covalently closed circular DNA (cccDNA) of nucleus in the infected hepatocytes, and this can result in HBV reactivation. ${ }^{3-5}$ So it is important to decrease and maintain serum HBV DNA level to the undetectable level as the ac-

\section{Abbreviations:}

$A D V$, adefovir; ALT, alanine aminotransferase; CHB, chronic hepatitis $B ; C V R$, complete virologic response; ETV, entecavir; $H B e A g$, hepatitis $B$ e antigen; HBV, hepatitis B virus; $\mathrm{HCC}$, hepatocellular carcinoma; NAs, nucleos(t)ide analogues; PVR, partial virologic response; RFMP, restriction fragment mass polymorphism; TDF, tenofovir; VR, virologic response

\author{
Corresponding author : Byung Seok Kim \\ Department of Internal Medicine, Catholic University of Daegu School of \\ Medicine, 33 DooRyoo Gongwon-ro 17 Gil, Namgu, Daegu 705-718, Korea \\ Tel: +82-53-650-4043, Fax: +82-53-656-3281 \\ E-mail:kbs9225@cu.ac.kr
}


tual purpose of treatment for $\mathrm{CHB}^{6-8}$ The current guidelines advise to check suboptimal responders by monitoring a virologic response at each timepoint in the use of nucleos(t)ide analogues (NAs), to provide an opportunity to modify a treatment so as to improve the antiviral efficacy. ${ }^{9,10}$

Partial virologic response (PVR) is defined as more than $2 \log _{10}$ $\mathrm{IU} / \mathrm{mL}$ decrease in HBV DNA but in detectable level by real-time PCR at week $24^{2,10}$ in the Korean Association for the Study of the Liver (KASL) and the American Association for the Study of Liver Disease (AASLD) guidelines or when a HBV DNA decreases more than $1 \log _{10} \mathrm{IU} / \mathrm{mL}$ but is detectable to the patients treated for at least 6 months with satisfactory compliance in the European Association for the Study of Liver (EASL) guidelines'. PVR is related to a failure of treatment, progression of liver damage, and usually increased risk of viral resistance. ${ }^{1,11}$ To determine changing drugs, measurement of PVR has been recommended at 24 week after treatment of lamivudine and telbivudine with low genetic barrier or 48 week after treatment of adefovir (ADV), entecavir (ETV) and tenofovir (TDF) with high genetic barrier, respectively. ${ }^{1,2,12,13}$

However, there has been a lot of controversy over the long-term prognosis prediction and the optimal treatment of patients with PVR to ETV. It is recommended to decide whether ETV monotherapy continue or not according to the HBV DNA level at week 48 and kinetics during 48 weeks. ${ }^{1,14}$ When an additional decline of HBV DNA does not occur in spite of favorable drug compliance, it is advised to add another drug in order to prevent the resistant virus in the long-term. However, we are still unsure whether or not combination treatment of ETV and other drug is more effective in case that a resistant virus is not certainly identified. Some studies showed that the virologic response rate kept increasing till after 1-4 years and the risk of resistance was low when even patients with PVR at week 48 were continuously treated with ETV monotherapy. ${ }^{11,13,15,16}$ Furthermore, HBV DNA level of higher than 7 to 8 $\log _{10} \mathrm{IU} / \mathrm{mL}$ before treatment, poor drug compliance, and high viral load during treatment are considered as factors which enable to predict the delayed treatment response in use of ETV. ${ }^{11,13,17}$

This study was designed to review the long-term duration (median follow-up duration 144 weeks, range 96-312 weeks) and cumulative treatment results on prolonged ETV monotherapy to the treatment-naive CHB patients with PVR, to compare the differences of factors between patients with VR within 48 weeks and patients with VR after 48 weeks, and to analyze an independent factor which predicts PVR at week 48.

\section{METHODS}

\section{Patients and follow-up}

This retrospective study included treatment-naïve CHB patients who were treated with $0.5 \mathrm{mg}$ ETV daily for more than 48 weeks between April 2007 and November of 2012 at Daegu Catholic University Hospital. CHB was defined as a detectable serum hepatitis B surface antigen (HBsAg) level for more than 6 months, serum HBV DNA level $\geq 20,000 \mathrm{IU} / \mathrm{mL}$ for hepatitis $B$ e antigen (HBeAg)-positive or $\geq 2,000 \mathrm{IU} / \mathrm{mL}$ for HBeAg-negative patients, and elevated serum alanine aminotransferase (ALT) levels. Patients with a history of previous NAs treatment, antibodies against hepatitis $C$ virus, or human immunodeficiency virus were excluded. In the anaylsis, 364 treatment-naïve CHB patients were included, which contained 28 patients diagnosed with HCC.

All patients were monitored at baseline and every 3 months during ETV therapy for the clinical assessment of tolerability, a physical examination, blood chemistry, HBV DNA level, HBeAg, and antibody against $\mathrm{HBeAg}$ (anti-HBe). The clinical diagnosis of cirrhosis was based on imaging findings (abdominal ultrasonography or computed tomography or magnetic resonance imaging) and compatible clinical features.

\section{Laboratory tests and definitions}

Serum HBV DNA was quantified by real-time polymerase chain reaction (PCR) assay using the COBAS Taq-Man HBV quantitative test (Roche Molecular Systems Inc., Branchburg, NJ, USA), which had a lower limit of quantification of $20 \mathrm{IU} / \mathrm{mL}$. Serum HBsAg, antibodies to $\mathrm{HBsAg}, \mathrm{HBeAg}$, and anti-HBe were detected by electrochemiluminescence immunoassay (Roche Diagnostics, Mannheim, Germany). Serum ALT normalization, HBeAg loss or seroconversion were monitored during follow-up. Complete virologic response (CVR) was defined as undetectable serum HBV DNA ( $<20 \mathrm{IU} / \mathrm{mL}$ ) by PCR at week $48 .{ }^{2}$ A virologic response (VR) was defined as undetectable HBV DNA $(<20 \mathrm{IU} / \mathrm{mL})$ by real-time $P C R$ assay during any treatment period, ${ }^{2}$ and delayed virologic response was defined as reaching VR after 48 weeks. Virologic breakthrough was defined as an increase in the serum HBV DNA level of more than $1 \log _{10} \mathrm{IU} / \mathrm{mL}$ from the nadir during continued treatment. ${ }^{2}$ When PVR developed at week 48, we checked for compliance. When a virologic breakthrough developed during the treatment period, we checked for compliance and tested a restriction fragment mass polymorphism (RFMP, Genematrix, Youngin, 
Korea) technology to identify the drug resistance mutation in the HBV polymerase gene. ${ }^{18,19}$

\section{Statistical analysis}

HBV DNA levels were logarithmically transformed for analysis. Continuous variables were expressed as the mean \pm standard deviation (SD) and categorical variables were expressed as frequencies. The chi-squared test was used to analyze categorical variables, and comparisons of continuous variables were analyzed using a $t$-test. Multiple linear regression analysis was applied to study which of pre or on-treatment factors were independently associated with the PVR to ETV monotherapy. The cumulative probability of achieving VR was estimated by way of Kaplan-Meier analysis. The $P$-values of $<0.05$ were considered statistically significant. Data was collected in Microsoft EXCEL (Microsoft Excel 2007; Microsoft Corp., Seattle, WA, USA) and analyzed using

Table 1. Baseline characteristics of the patients

\begin{tabular}{lc}
\hline Variables & Patients $(\mathbf{n}=\mathbf{3 6 4})$ \\
\hline Age $(\mathrm{yr})$ & $51.1 \pm 11.9$ \\
Male & $200(54.9)$ \\
Cirrhosis & $202(55.5)$ \\
ALT (IU/L) & $217.5 \pm 415.3$ \\
Baseline HBV DNA $\left(\log _{10} \mathrm{IU} / \mathrm{mL}\right)$ & $8.2 \pm 9.0$ \\
HBeAg positivity & $202(55.5)$ \\
HCC & $28(7.7)$ \\
\hline
\end{tabular}

Data are presented as mean \pm SD or number $(\%)$.

ALT, alanine aminotransferase; HBV, hepatitis B virus; HBeAg, hepatitis B e antigen; HCC, hepatocellular carcinoma.
SPSS version 19.0 for Windows (SPSS Inc., Chicago, IL, USA).

\section{RESULTS}

\section{Baseline characteristics of study patients}

The baseline characteristics of the patients are summarized in Table 1. A total of 364 patients were enrolled between April 2007 and November 2012. All patients were treatment-naïve and received $0.5 \mathrm{mg}$ of ETV once daily for more than 12 months. The mean age of the patients was $51.1 \pm 11.9$ years. There were 200 men (54.9\%) and 202 patients (55.5\%) with cirrhosis. The mean baseline serum ALT level was $217.5 \pm 415.3 \mathrm{IU} / \mathrm{L}$ and the serum HBV DNA level was $8.2 \pm 9.0$ $\log _{10} \mathrm{IU} / \mathrm{mL}$. Of the total 364 patients, 202 patients (55.5\%) were HBeAg-positive and 162 patients (44.5\%) were HBeAg-negative. Of the 28 patients with HCC, their staging according to modified Union for International Cancer Control (UICC) classification were I in 4 patients, II in 10 patients, III in 13 patients, and IVA in 1 patient, and their staging according to Barcelona Clinic Liver Cancer (BCLC) classification were $A$ in 16 patients, $B$ in 7 patients, and $C$ in 5 patients. In the HCC group, 9 patients were treated by surgical resection, 5 patients were treated by radiofrequency ablation, 12 patients were treated by transcatheter arterial chemoembolization, 1 patient was treated by sorafenib, and 1 patient had no treatment.

\section{Efficacy of ETV therapy at week 48}

Of the 364 patients, 312 patients (85.7\%) had CVR, but 52

Table 2. Characteristics of seven patients whose treatment was adapted

\begin{tabular}{|c|c|c|c|c|c|c|c|}
\hline Patient & $\begin{array}{c}1 \\
\text { (TDF) }\end{array}$ & $\begin{array}{c}2 \\
\text { (TDF) }\end{array}$ & $\begin{array}{c}3 \\
\text { (TDF) }\end{array}$ & $\begin{array}{c}4 \\
\text { (TDF) }\end{array}$ & $\begin{array}{c}5 \\
\text { (TDF) }\end{array}$ & $\begin{array}{c}6 \\
\text { (TDF) }\end{array}$ & $\begin{array}{c}7 \\
(E T V+A D V)\end{array}$ \\
\hline Age (yr) & 24 & 33 & 36 & 28 & 22 & 48 & 37 \\
\hline Gender & Male & Male & Male & Male & Male & Female & Male \\
\hline HBeAg & Positive & Positive & Positive & Positive & Positive & Negative & Positive \\
\hline Baseline HBV DNA (IU/mL) & $4.1 \times 10^{8}$ & $2.3 \times 10^{6}$ & $1.1 \times 10^{9}$ & $1.1 \times 10^{10}$ & $2.3 \times 10^{8}$ & $2.8 \times 10^{8}$ & $4.3 \times 10^{8}$ \\
\hline ALT (IU/L) & 95 & 33 & 120 & 59 & 73 & 86 & 69 \\
\hline HBV DNA at week 48 (IU/mL) & $6,990,000$ & 1,210 & 724 & 2,070 & 1,140 & 121 & 66,200 \\
\hline HBV mutant & - & - & - & - & - & - & $\begin{array}{c}\text { rtL180M } \\
\text { rtM204V } \\
\text { rtS202G }\end{array}$ \\
\hline $\begin{array}{l}\text { Time of treatment adaptation after PVR } \\
\text { (weeks) }\end{array}$ & 156 & 68 & 52 & 68 & 44 & 60 & 80 \\
\hline
\end{tabular}

TDF, tenofovir; ETV, entecavir; ADV, adefovir; HBeAg, hepatitis B e antigen; HBV, hepatitis B virus; ALT, alanine aminotransferase. 
(14.3\%) had PVR at week 48. In HBeAg-positive patients, 155 of 202 patients (76.5\%) achieved VR and in HBeAg-negative patients, 157 of 162 patients (97\%) achieved VR for a year. Overall mean reductions in serum HBV DNA levels from baseline were $-6.0 \pm 1.5 \log _{10} \mathrm{IU} / \mathrm{mL}$. Thirteen CVR patients (4.2\%) and 7 PVR patients $(13.5 \%)$ showed virologic breakthrough during 48 weeks therapy. At first, we checked and encouraged compliance to these patients and continued prolonged ETV monotherapy. And then, we performed genetic mutation test in 6 patients who had kept drug compliance (1 patient in CVR and 5 patients in PVR at 48 weeks), and there was no genotypic resistance to ETV by RFMP analysis. Of the 52 patients with PVR at 48 weeks, their HBV DNA levels were categorized as 24 patients (46.2\%) whose titer above than 1,000 IU/mL, 12 patients (23.0\%) whose titer of 1,000-100 $\mathrm{IU} / \mathrm{mL}$, and 16 patients (30.8\%) whose titer of $100-21 \mathrm{IU} / \mathrm{mL}$.

\section{Outcomes during continuous ETV therapy}

Among the patients with PVR at week 48, 6 switched to TDF monotherapy, 1 switched to ETV+ADV combination therapy, and there were 4 of follow-up loss. We summarized characteristics of 7 patients who changed the regimen of therapy in Table 2. Except for them, 41 patients with PVR at week 48 were treated with prolonged ETV monotherapy for over 96 weeks (Fig.1, median followup duration 144 weeks, range 96-312 weeks). Among these patients for 96 weeks, thirty-two (78.0\%) of 41 patients achieved a VR beyond week 48. Moreover, 8 patients needed more than 96 weeks of continuous ETV therapy to achieve a VR.

The overall cumulative rates of VR at week 96, 144, 192 were $78.0 \%, 92.7 \%$ and $95.1 \%$, respectively (Fig. 2, median duration of reaching VR was 78 weeks, range $60-288$ weeks). The rates of VR were $97.2 \%$ (35/36) in HBeAg-positive patients and 100\% (5/5) in HBeAg-negative patients, and the overall rates of virologic breakthrough during follow-up was $14.6 \%(n=6)$. The patients with virologic breakthrough were educated to keep drug compliance and a genetic resistance test was performed for them. There was no one with genetic resistance and 5 patients achieved VR again during follow-up.

The overall rates of ALT normalization and HBeAg seroconversion during follow-up were observed in $97.6 \%(n=40)$ and $2.5 \%$ $(n=1)$ of patients, respectively. Among those who had PVR at week 48, a 30-year-old male HBeAg-positive CHB patient with 7.3 $\log _{10} \mathrm{IU} / \mathrm{mL}$ of baseline HBV DNA, whose drug compliance was fine. His viral load steadily decreased and stagnated in 100-1,000 $\mathrm{IU} / \mathrm{mL}$ at week 60 . He could not visit to our hospital from personal reasons when drug modification was considered according to the virologic breakthrough at week 120 .

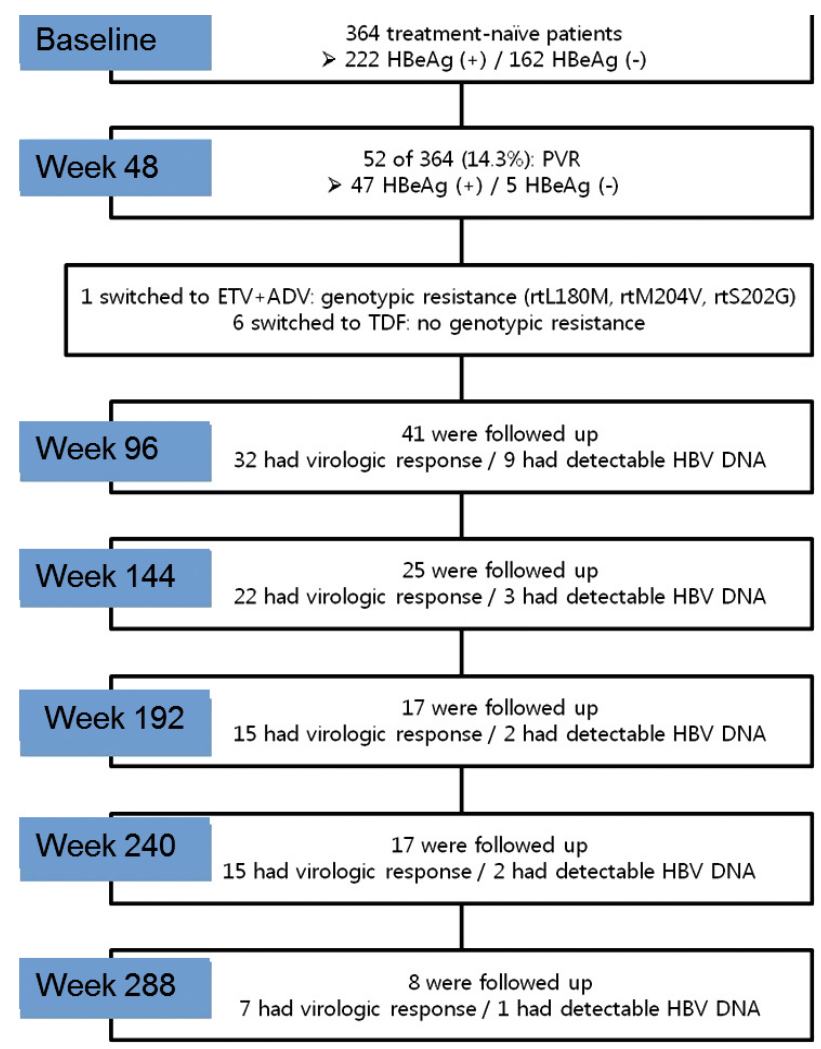

Figure 1. Flow diagram of the enrolled patients. HBeAg, hepatitis B e antigen; PVR, partial virologic response; ETV, entecavir; ADV, adefovir; TDF, tenofovir; HBV, hepatitis B virus.

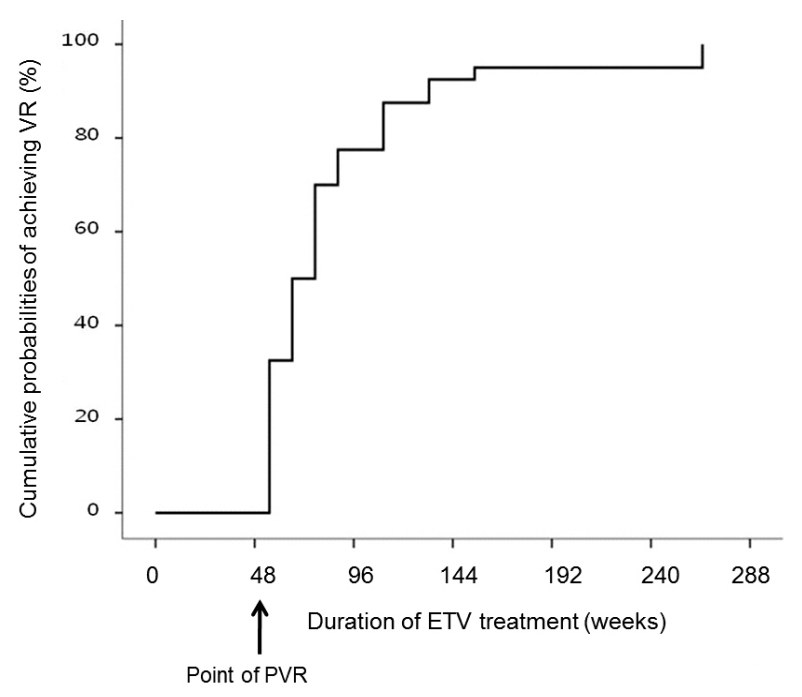

Figure 2. Cumulative probabilities of achieving virologic response during prolonged entecavir monotherapy for $\geq 96$ weeks in patients with partial virologic response at week 48 by Kaplan-Meier analysis. 


\section{Factors associated with delayed virologic response}

In comparison with characteristics in the patients with complete virologic responders and delayed virologic responders, there was no significant difference among age, gender, cirrhosis, and HCC (Table 3). HBeAg positivity (49.5\% vs. 90\%; $P<0.001)$, baseline HBV DNA level $\left(6.0 \pm 1.5 \log _{10} \mathrm{IU} / \mathrm{mL}\right.$ vs. $7.4 \pm 1.6 \log _{10} \mathrm{IU} / \mathrm{mL}$; $P<0.001)$, HBV DNA level at week $12\left(1.1 \pm 1.4 \log _{10} \mathrm{IU} / \mathrm{mL}\right.$ vs. $\left.3.3 \pm 1.3 \log _{10} \mathrm{IU} / \mathrm{mL} ; P<0.001\right)$, and HBV DNA level at week 24 $\left(0.5 \pm 1.1 \log _{10} \mathrm{IU} / \mathrm{mL}\right.$ vs. $\left.2.8 \pm 1.8 \log _{10} \mathrm{IU} / \mathrm{mL} ; P<0.001\right)$ were higher in delayed virologic responders than in patients with CVR, but initial ALT level (235.9 $\pm 445.9 \mathrm{IU} / \mathrm{L}$ vs. $127.2 \pm 125.9 \mathrm{IU} / \mathrm{L} ; P=0.001)$, HBeAg loss (34.5\% vs. 5\%; $P=0.004)$, HBeAg seroconversion ( $22.7 \%$ vs. $2.5 \% ; P=0.003$ ) were higher in patients with CVR than in delayed virologic responders.

The duration of reaching VR of the delayed virologic responders was much longer $(4.7 \pm 3.5$ months vs. $26.3 \pm 15.5$ months; $P<0.001)$ but no difference was found in ALT normalization $(96.7 \%$ vs. $97.5 \% ; P=0.981)$ and VR rate (100\% vs. $97.6 \% ; P=1.000)$. In multivariate analysis, HBeAg positivity (odds ratio [OR], 9.231; 95\% confidence interval $[\mathrm{Cl}], 1.03-82.91 ; P=0.047)$ and a high baseline HBV DNA level (OR, 0.170; 95\% Cl, 0.08-0.37; $P=0.000)$ were independently associated with a delayed virologic response (Table 4).

\section{DISCUSSION}

In a less potent antiviral agent prior to ETV, achieving VR at a certain timepoint was an important predictor which helps expect

Table 3. Comparison of clinical features between patients exhibiting complete and delayed virologic responses

\begin{tabular}{|c|c|c|c|}
\hline Variables & $\begin{array}{l}\text { Complete virologic response } \\
\qquad(\mathrm{n}=312)\end{array}$ & $\begin{array}{l}\text { Delayed virologic response } \\
\qquad(n=40)\end{array}$ & $P$-value \\
\hline Age (yr) & $52.1 \pm 11.6$ & $48.8 \pm 11.3$ & 0.097 \\
\hline Male & $165(53.4)$ & $22(55)$ & 0.624 \\
\hline Cirrhosis & $163(52.8)$ & $13(32.5)$ & 0.078 \\
\hline $\mathrm{HCC}$ & $24(7.8)$ & $3(7.5)$ & 0.953 \\
\hline HBeAg positivity & $153(49.5)$ & $36(90)$ & $<0.001$ \\
\hline ALT (IU/L) & $235.9 \pm 445.9$ & $127.2 \pm 125.9$ & 0.001 \\
\hline ALT normalization & $294(96.7)$ & $39(97.5)$ & 0.981 \\
\hline HBeAg loss & $77(34.5)$ & $2(5)$ & 0.004 \\
\hline HBeAg seroconversion & $51(22.7)$ & $1(2.5)$ & 0.003 \\
\hline Baseline HBV DNA $\left(\log _{10} \mid \mathrm{U} / \mathrm{mL}\right)$ & $6.0 \pm 1.5$ & $7.4 \pm 1.6$ & $<0.001$ \\
\hline HBV DNA at week $12\left(\log _{10} 1 \mathrm{U} / \mathrm{mL}\right)$ & $1.1 \pm 1.4$ & $3.3 \pm 1.3$ & $<0.001$ \\
\hline HBV DNA at week $24\left(\log _{10} \mathrm{IU} / \mathrm{mL}\right)$ & $0.5 \pm 1.1$ & $2.8 \pm 1.8$ & $<0.001$ \\
\hline Mean duration of reaching VR (months) & $4.7 \pm 3.5$ & $26.3 \pm 15.5$ & $<0.001$ \\
\hline
\end{tabular}

Data are presented as mean \pm SD or number (\%).

CVR, complete virologic response; HCC, hepatocellular carcinoma; HBeAg, hepatitis B e antigen; ALT, alanine aminotransferase; HBV, hepatitis B virus; VR, virologic response.

Table 4. Factors associated with delayed virologic response during entecavir therapy by multivariate analysis

\begin{tabular}{lccc}
\hline Variables & OR & 95\% Cl & $P$-value \\
\hline HBeAg positivity & 9.231 & $1.03-82.91$ & 0.047 \\
ALT $(I U / L)$ & 0.998 & $0.99-1.00$ & 0.353 \\
HBeAg loss & 3.342 & $0.32-35.33$ & 0.316 \\
HBeAg seroconversion & 1.462 & $0.10-20.94$ & 0.780 \\
Baseline HBV DNA $\left(\log _{10} \mid \mathrm{U} / \mathrm{mL}\right)$ & 0.170 & $0.08-0.37$ & 0.000 \\
HBV DNA at week $12\left(\log _{10} \mathrm{IU} / \mathrm{mL}\right)$ & 1.850 & $0.81-4.22$ & 0.143 \\
HBV DNA at week $24\left(\log _{10} \mathrm{IU} / \mathrm{mL}\right)$ & 0.426 & $0.18-1.01$ & 0.052 \\
\hline
\end{tabular}

$\mathrm{OR}$, odds ratio; $\mathrm{Cl}$, confidence interval; $\mathrm{HBeAg}$, hepatitis $\mathrm{B}$ e antigen; $\mathrm{ALT}$, alanine aminotransferase; $\mathrm{HBV}$, hepatitis B virus. 
the long-term treatment response. It is reported that reaching a VR of lamivudine and telbivudine at week 24, and of ADV at week 48 is related to the lower incidence of resistance, improved chance of maintained VR in both HBeAg-positive and HBeAg-negative patients, and higher chance of HBeAg seroconversion in the HBeAg-positive patients. ${ }^{12,20-23}$ It is not a failure of the initial treatment, but the current guidelines recommend considering treatment adaptation because PVR without achieving VR at timepoints has a greater risk of genetic resistance during ETV therapy. ${ }^{1,11,13}$ Though these on-treatment predictors can be useful for treatment with above mentioned antiviral agents, they can differ for each drug and their usefulness in ETV as a predictor at timepoints based on the study of the previous less potent drugs is not established. ${ }^{1}{ }^{14}$

The ETV is, as to TDF, a drug with a high genetic barrier barrier and its antiviral potency is more extraordinary than the previous NAs. From a study on the treatment result of ETV, the VR rate of HBeAg-positive patients was $67 \%{ }^{24}$ for a year and $90 \%{ }^{16,25}$ for more than 3 years. The VR rate of HBeAg-negative patients was $90 \%{ }^{26}$ for a year and over $95 \%{ }^{27}$ for $3-5$ years. In terms of resistance incidence, it was reported that the cummulative resistance rate was $1.2 \%$ at 5 year of ETV therapy. ${ }^{25,28}$ The former clinical and virological studies say that drug compliance test and drug resistance test are necessary and treatment adaptation should be considered as soon as possible when an oral antiviral agent is used and virologic breakthrough is shown. ${ }^{29-35}$ According to other studies, it is very likely that one reason why virologic breakthrough is shown during ETV treatment to NAs-naive patients is mostly poor compliance of patients. ${ }^{28,36}$ Then they report that the encouragement of patients' drug compliance and continuous ETV treatment are helpful in inhibiting a virus in the long-term. ${ }^{28,36}$

In the multicenter cohort study by Zoutendijk et al, thirty-six patients (21\%) with PVR at week 48 among patients treated with ETV monotherapy continued the treatment. Twenty-nine of them (81\%) reached VR beyond 48 weeks, and 10 of them did beyond 96 weeks. During follow-up of 3 years, no one had resistance to ETV and 21 of 22 patients (95\%) with HBV DNA $<1,000 \mathrm{IU} / \mathrm{mL}$ at week 48 reached VR compared with 8 of 14 patients (57\%) with HBV DNA $\geq 1,000 \mathrm{IU} / \mathrm{mL}$. This means that a case of HBV DNA $\geq 1,000 \mathrm{IU} / \mathrm{mL}$ at week 48 is a factor to predict a delayed treatment response. ${ }^{13}$

In the open-label prospective studies by Ko et al, 18 patients (14\%) who received ETV monotherapy for more than one year and showed PVR at week 48 among 128 of naïve CHB patients continued the treatment. Based on the monitoring result for 2 years, 9 of 13 patients (69.2\%) reached VR. According to this study, the independent factor to predict PVR was a substantial viral load ( $>7$ $\log _{10} \mathrm{IU} / \mathrm{mL}$ ) from the baseline and was not relevant to a result of HBeAg test, presence of liver cirrhosis, and ALT level."

Upon the retrospective study by Kwon et al, ETV monotherapy was constantly performed to 64 patients $(28.2 \%)$ who received ETV treatment for more than one year and showed PVR at week 48 among 227 naïve CHB patients. As the patients were monitored for 3 years, the cumulative rate of VR was $45.2 \%$ at week 96 and $73.8 \%$ at week 144 , and the rate of resistance was not different from the early VR patients group. This study showed the independent factor to predict PVR was a case of more than $8 \log _{10}$ $\mathrm{IU} / \mathrm{mL}$ of serum HBV DNA from the baseline, more than 2,000 IU/ $\mathrm{mL}$ of serum HBV DNA at week 12, and when a serum HBV DNA was detectable at week $24 .^{17}$

The PVR rate of ETV treatment in this study was similar or lower compared to the former studies. The rate of VR was quite high; $76.5 \%$ in HBeAg-positive patients and $97 \%$ in HBeAg-negative patients for a year. We monitored the viral loads of treatment-naive patients with PVR and continuously maintained ETV monotherapy as long as genetic mutation was not detected in spite of virologic breakthrough. It resulted that 40 of 41 patients who were followed up for more than 6 years reached the VR. This VR rate (97.6\%) was higher than those of any previous studies and no one showed genetic mutation. As mentioned in other previous studies, this indicates the strong antiviral effect of ETV and its safety. Even though it did not make patients to reach VR in a short time, the treatment effect still maintained after prolonged treatment.

Furthermore, the initial high level of HBV DNA was shown to be an independent factor that enabled to predict the delayed virologic response in this study, and it matches the result of previous studies. The HBV DNA level at week 12 or 24 was not predictive of delayed virologic response although it has significant difference from that of CVR patients group. What we newly found is that the initial HBeAg positivity can be an independent factor to predict the delayed virologic response. Because most people with PVR at week 48 reached VR, we could not find out any predictive factor for VR. According to the study of Ko et al, the rate of delayed virologic response was determined by the level of $1,000 \mathrm{IU} / \mathrm{mL}$ in $\mathrm{HBV}$ DNA at week $48 .{ }^{11}$ However, in our study, the rate (39\%) of delayed virologic response of 16 patients whose HBV DNA level was more than $1,000 \mathrm{IU} / \mathrm{mL}$ at week 48 did not show a significant difference from that (61\%) of 25 patients whose HBV DNA level was less than 1,000 IU/mL at week 48 . 
While only treatment-naïve patients were followed up in our study, the patients who experienced oral antiviral agents were included in some studies. They reported that the PVR rate of patients with lamivudine-resistance was significantly high and that poor VR and ETV-resistance could be predicted by the occurrence of PVR at week 24 or 48 . $^{18,37}$ Therefore, in treatment-experienced CHB patients, an adequate plan of treatment monitoring and adaptation should be made through detailed history taking and drug resistance test in use of oral antiviral agents.

Our study has some limitations. First, as this study is a retrospective study and was performed at a single tertiary care center, characteristics of patients could be limited. And the patients with PVR were very few, so there is a limitation in regarding this result as a general idea of monitoring for more than 6 years. However, several studies on the prolonged ETV treatment reported the high rate of achieving VR and its safety recently. They become basis on monotherapy without treatment adaptation. Therefore, it is necessary to discuss the prolonged ETV treatment based on these studies in treatment-naïve CHB patients.

Second, outcome might be different if 7 treatment-adapted patients with PVR have prolonged ETV monotherapy. It was appropriate to change the treatment to one patient because he showed genetic mutation after PVR, but the other 6 patients could have chances to be in prolonged ETV monotherapy. Although the number of patients was small, this point has probabilities to affect the results of our study.

In conclusion, long-term ETV monotherapy is effective for achieving VR in treatment-naïve CHB patients with PVR to ETV. HBeAg positivity and a high baseline HBV DNA level were independently associated with a delayed virologic response. Additional studies about optimal management of patients with PVR to ETV are necessary.

\section{Conflicts of Interest}

The authors have no conflicts to disclose.

\section{REFERENCES}

1. European Association for the Study Of The Liver. EASL Clinical Practice Guidelines: Management of chronic hepatitis B. J Hepatol 2012;57:167185.

2. Korean Association for the Study of the Liver. KASL Clinical Practice Guidelines: Management of chronic hepatitis B. Clin Mol Hepatol 2012;18:109-162.
3. Raimondo G, Allain JP, Brunetto MR, Buendia MA, Chen DS, Colombo $M$, et al. Statements from the Taormina expert meeting on occult hepatitis B virus infection. J Hepatol 2008;49:652-657.

4. Brechot C, Hadchouel M, Scotto J, Fonck M, Potet F, Vyas GN, et al. State of hepatitis B virus DNA in hepatocytes of patients with hepatitis $B$ surface antigen-positive and -negative liver diseases. Proc Natl Acad Sci USA 1981;78:3906-3910.

5. Brechot C, Thiers V, Kremsdorf D, Nalpas B, Pol S, Paterlini-Brechot P. Persistent hepatitis $B$ virus infection in subjects without hepatitis B surface ntigen: clinically significant or purely "occult"? Hepatology 2001;34:194-203.

6. Liaw YF. Hepatitis B virus replication and liver disease progression: the impact of antiviral therapy. Antivir Ther 2006;11:669-679.

7. Mommeja-Marin H, Mondou E, Blum MR, Rousseau F. Serum HBV DNA as a marker of efficacy during therapy for chronic HBV infection: analysis and review of the literature. Hepatology 2003;37:1309-1319.

8. Yuan HJ, Yuen MF, Ka-Ho Wong D, Sablon E, Lai CL. The relationship between HBV-DNA levels and cirrhosis-related complications in Chinese with chronic hepatitis B. J Viral Hepat 2005;12:373-379.

9. Liaw Y-F, Leung N, Kao J-H, Piratvisuth T, Gane E, Han K-H, et al. Asian-Pacific consensus statement on the management of chronic hepatitis B: a 2008 update. Hepatol Int 2008;2:263-283.

10. Lok ASF, McMahon BJ. Chronic hepatitis B: update 2009. Hepatology 2009:50:661-662.

11. Ko SY, Choe WH, Kwon SY, Kim JH, Seo JW, Kim KH, et al. Long-term impact of entecavir monotherapy in chronic hepatitis B patients with a partial virologic response to entecavir therapy. Scand J Gastroenterol 2012;47:1362-1367.

12. Lai $\mathrm{CL}$, Gane E, Liaw YF, Hsu CW, Tongsawat S, Wang Y, et al. Telbivudine versus lamivudine in patients with chronic hepatitis B. N Engl J Med 2007;357:2576-2588

13. Zoutendijk R, Reijnders JG, Brown A, Zoulim F, Mutimer D, Deterding $K$, et al. Entecavir treatment for chronic hepatitis $B$ : adaptation is not needed for the majority of naive patients with a partial virological response. Hepatology 2011;54:443-451.

14. Lampertico P. Partial virological response to nucleos(t)ide analogues in naive patients with chronic hepatitis B: From guidelines to field practice. J Hepatol 2009;50:644-647.

15. Ono A, Suzuki F, Kawamura Y, Sezaki H, Hosaka T, Akuta N, et al. Long-term continuous entecavir therapy in nucleos(t)ide-naive chronic hepatitis B patients. J Hepatol 2012;57:508-514.

16. Yuen MF, Seto WK, Fung J, Wong DK, Yuen JC, Lai CL. Three years of continuous entecavir therapy in treatment-naive chronic hepatitis $B$ patients: viral suppression, viral resistance, and clinical safety. Am J Gastroenterol 2011;106:1264-1271.

17. Kwon DH, Kim IH, Choung BS, Ahn DS, Yoo SH, Park SB, et al. Continuous long-term ETV therapy in naive CHB patients showing PVR. Gut Liver 2013;7:712-718. 
18. Hong SP, Kim NK, Hwang SG, Chung HJ, Kim S, Han JH, et al. Detection of hepatitis $B$ virus YMDD variants using mass spectrometric analysis of oligonucleotide fragments. J Hepatol 2004;40:837-844.

19. Han KH, Hong SP, Choi SH, et al. Comparison of multiplex restric $\neg$ tion fragment mass polymorphism and sequencing analyses for detecting entecavir resistance in chronic hepatitis B. Antivir Ther 2011;16:77-87.

20. Hadziyannis SJ, Tassopoulos NC, Heathcote EJ, Chang TT, Kitis G, Rizzetto $\mathrm{M}$, et al. Long-term therapy with adefovir dipivoxil for $\mathrm{HBeAg}$ negative chronic hepatitis B for up to 5 years. Gastroenterology 2006;131:1743-1751.

21. Yuen MF, Sablon E, Hui CK, Yuan HJ, Decraemer H, Lai CL. Factors associated with hepatitis $B$ virus DNA breakthrough in patients receiving prolonged lamivudine therapy. Hepatology 2001;34:785-791.

22. Zeuzem S, Gane E, Liaw YF, Lim SG, DiBisceglie A, Buti M, et al. Baseline characteristics and early on-treatment response predict the outcomes of 2 years of telbivudine treatment of chronic hepatitis B. J Hepatol 2009;51:11-20.

23. Liaw $Y F$, Gane $E$, Leung $N$, Zeuzem $S$, Wang $Y$, Lai $C L$, et al. 2-Year GLOBE trial results: telbivudine is superior to lamivudine in patients with chronic hepatitis B. Gastroenterology 2009;136:486-495.

24. Chang TT, Gish RG, de Man R, Gadano A, Sollano J, Chao YC, et al. A comparison of entecavir and lamivudine for $\mathrm{HBeAg}$-positive chronic hepatitis B. N Engl J Med 2006;354:1001-1010.

25. Chang TT, Lai CL, Kew YS, Lee SS, Coelho HS, Carrilho FJ, et al. Entecavir treatment for up to 5 years in patients with hepatitis $B$ e antigenpositive chronic hepatitis B. Hepatology 2010;51:422-430.

26. Lai CL, Shouval D, Lok AS, Chang TT, Cheinquer H, Goodman Z, et al. Entecavir versus lamivudine for patients with $\mathrm{HBeAg-negative} \mathrm{chronic}$ hepatitis B. N Engl J Med 2006;354:1011-1020.

27. Shouval D, Lai C-L, Chang T-T, Gadano A, Wu S-S, Halota W, et al. Three years of entecavir (ETV) re-treatment of HBeAg(-) ETV patients who previously discontinued ETV treatment: results from study ETV901. Hepatology 2008:48:722A.

28. Tenney DJ, Rose RE, Baldick CJ, Pokornowski KA, Eggers BJ, Fang J, et al. Long-term monitoring shows hepatitis $B$ virus resistance to en- tecavir in nucleoside-naïve patients is rare through 5 years of therapy. Hepatology 2009;49:1503-1514.

29. Lampertico P, Vigano $P$, Manenti $E$, lavarone M, Lunghi G, Colombo M. Adefovir rapidly suppresses hepatitis B in HBeAg-negative patients developing genotypic resistance to lamivudine. Hepatology 2005;42: $1414-1419$

30. Kim do Y, Ahn SH, Lee HW, Park JY, Kim SU, Paik YH, et al. Clinical course of virologic breakthrough after emergence of $\mathrm{YMDD}$ mutations in HBeAg-positive chronic hepatitis B. Intervirology 2008;51:293-298.

31. Lee JM, Park JY, Kim do Y, Nguyen T, Hong SP, Kim SO, et al. Longterm adefovir dipivoxil monotherapy for up to 5 years in lamivudineresistant chronic hepatitis B. Antivir Ther 2010;15:235-241.

32. Lee JM, Kim HJ, Park JY, Lee CK, Kim do Y, Kim JK, et al. Rescue monotherapy in lamivudine-resistant hepatitis $B$ e antigen-positive chronic hepatitis B: adefovir versus entecavir. Antivir Ther 2009;14:705-712.

33. Kim H, Han K, Ahn SH, Kim EO, Chang HY, Moon MS, et al. Evaluation of methods for monitoring drug resistance in chronic hepatitis $B$ patients during lamivudine therapy based on mass spectrometry and reverse hybridization. Antivir Ther 2005;10:441-449.

34. Han KH, Hong SP, Choi SH, Shin SK, Cho SW, Ahn SH, et al. Comparison of multiplex restriction fragment mass polymorphism and sequencing analyses for detecting entecavir resistance in chronic hepatitis B. Antivir Ther 2011;16:77-87.

35. Papatheodoridis GV, Dimou E, Dimakopoulos K, Manolakopoulos S, Rapti I, Kitis G, et al. Outcome of hepatitis B e antigen-negative chronic hepatitis $B$ on long-term nucleos(t)ide analog therapy starting with lamivudine. Hepatology 2005;42:121-129.

36. Yang YJ, Shim JH, Kim KM, Lim YS, Lee HC. Assessment of current criteria for primary nonresponse in chronic hepatitis $B$ patients receiving entecavir therapy. Hepatology 2014;59:1303-1310.

37. Chen $\mathrm{CH}$, Hu TH, Hung CH, Wang JH, Lu SN, Lee CM. Antiviral effect of entecavir in nucleos(t)ide analogue-na€ive and nucleos(t)ide analogueexperienced chronic hepatitis B patients without virological response at week 24 or 48 of therapy. Journal of Viral Hepatitis 2014;21:e55e64. 